\title{
Do consumers' values and attitudes affect food retailer choice? Evidence from a national survey on farmers' market in Germany
}

\author{
Gianni Cicia, Marilena Furno ${ }^{*}$ and Teresa Del Giudice
}

\author{
*Correspondence: marfurno@unina. \\ Department of Agricultural \\ Sciences, Università degli Studi di \\ Napoli "Federico II", Naples, Italy
}

\begin{abstract}
New trends in food consumption are shaping consumers' preferences and buying behavior. Non-traditional food retailing and short supply chains (SSCs) are offering bundles of attributes that fit the needs of larger consumers' segments. Several studies have analyzed factors affecting the choice of traditional and non-traditional food retailing. Very few, however, are those studies that analyze the predictive role of human values and attitudes on the choice of traditional and non-traditional food retailing and supply chains. Usually, due to the low percentage of consumers involved in SSC, analyses of consumer behavior have been conducted using convenience samples. This study, based on online questionnaires submitted to a representative sample composed by 1009 German consumers, tests the hypothesis that the frequency of purchases at farmers' markets is related to human values: attitude toward the industrialized food market and attitude toward the environment. The econometric approach here implemented computes the model on average and in the tails of the dependent variable, frequency of purchases at farmers' market, thus investigating the model in a representative sample even where the percentage of non-traditional food retailing consumers is low, as occurs in the tails for low/high frequency of purchases. The questionnaire included the Schwartz value survey, attitudes toward environment and attitude toward industrialized food market, and self-reported estimates of the frequency of buying at farmers' market. Results suggest that the frequency of buying at farmers' market is hierarchically related to attitudes and values. The frequency of purchases at farmers' market is negatively related to industrialized food attitude and positively related to pro-environment attitude. Attitudes are in turn affected by values: self-transcendence has a positive impact on pro-environment attitude and the reverse is true for conservation. Furthermore, these relationships are not constant in the sample: they change according to the selected frequency of purchases.
\end{abstract}

Keywords: Farmers' market, Cognitive hierarchical model, Expectile regression, Mode regression 


\section{Introduction}

In recent years, agricultural commodity markets have experienced new trends. The key element in this process is the shift from a productivist to a post-productivist food regime (Renting et al. 2003). Food markets are becoming increasingly differentiated thanks to the emergence of new forms of food distribution organization in addition to existing anonymous mass food markets (Marsden 1998). Such new organizations, termed short supply chains (SSCs), are characterized by the direct relationship between the producer and the consumer or by a small number of trade intermediaries (D'Amico et al. 2014). Direct agricultural markets allow consumers to be involved (co-producers), while this is not the case in conventional retailers (Hinrichs 2000; Mennella 2019). Renting et al. (2003) identified eight different organizations for direct sales of locally produced food (SSC structures): farmers' markets, farm shops, pick-your-own, roadside markets, mail order, e-commerce, box schemes, and home deliveries.

In this paper, we focus on farmers' markets (FMs) that can be considered a sustainable alternative to global markets (Goodman 2004; Roos et al. 2007; Gallenti et al., 2016; Giampietri et al. 2016; Giampietri et al. 2018), with specific impacts on economic sustainability, environmental sustainability, social sustainability, human health (food quality and well-being), and ethical concerns. All these elements produce a different food quality structure related not only to classic product attributes (taste, safety, locally grown products, freshness, etc.), but also to social and ethical criteria (Goodman 2004; Migliore et al. 2012). Alkon (2008) found that consumers who buy products at FMs perceive vendors as driven by moral values in contrast to the classical industrial agribusiness system mainly driven by profit. In this scenario, consumer participation in FMs is dictated by preferences for particular intrinsic and extrinsic product attributes and by deeper factors, such as attitudes and personal values (Migliore et al. 2015).

By attitudes, we mean the extent of a person's favorable or unfavorable evaluation of a specific behavior (Ajzen and Driver 1992). There is an extensive literature on how attitudes help explain food choice (Thompson et al. 1994). Indeed, the literature on FMs suggests that consumers participating in SSCs have, on average, a favorable evaluation of pro-environmental choices and an unfavorable evaluation of modern agri-food systems. On the other hand, human values have been described as abstract and enduring concepts that guide or explain attitudes, norms, beliefs, and behavior (Rokeach 1973; Schwartz 1992). Important research fields in consumer studies analyze how consumers are related to their choice of product through an understanding of their values. Following this approach, the value of the abstract concept is linked to the concrete action through the attitude which is a mediating variable, and this successive event is called the value-attitude-behavior hierarchy (Homer and Kahle 1988)

Research into values is prominent in the literature, and the consumer's concern vis-àvis ethical issues represents a topic of great interest. Besides, understanding how values are able to explain consumer attitudes and behavior may offer insights into how ethical beliefs can drive participation in alternative food distribution organizations.

The hypotheses behind this work are (1) attitudes toward industrialized food markets influence behavior, (2) attitudes towards the environment influence behavior, and (3) the system of individuals' personal values influences the choice of buying at FMs. We will test the existence of a hierarchical relationship between human values, measured through the lens of Schwartz values, attitudes toward industrialized food markets and 
the environment, and the purchase frequency at farmers' markets, through a cognitive hierarchy model (CHM) (Homer and Kahle 1988). The CHM allows us to evaluate whether there is a direct relationship between the individual's value system and the choice of buying at FMs. In addition, the CHM allows us to check whether this value system is mediated by specific attitudes toward the agro-industrial system and the environment. Specific belief and attitude are more likely to predict behaviors than more general measures like values. Moreover, this approach also avoids attitude-intentionbehavior bias (McEachern et al. 2005; Vermeir and Verbeke 2006) because the CHM assumes a relationship between values, attitudes, and behavior not mediated by intention.

For this purpose, a survey was conducted within Germany. Although there are no official statistics on farmers' markets in this country, it has been estimated that approximately 30,000-40,000 farmers sell products directly at the farm or at farmers' markets, accounting for about $6-8 \%$ of German farms (Irz et al. 2015).

Analyses of purchase behavior at farmers' markets are usually conducted using convenience samples (Zinkhan et al. 1999; Migliore et al. 2015; Giampietri et al. 2018). Traditionally, the use of this kind of sample is due to the need to specifically "get into the field": to investigate a precise segment of the population with a small sample size, namely subjects who are experienced in non-traditional retail and provide reliable elicited answers. This paper is the first attempt to explain such behavior in a large sample. Data were collected through a questionnaire submitted to a representative, stratified sample of 1009 German consumers.

Finally, in this paper, we estimated the CHM not only on average, by least squares, but also in the tails, at low/high frequency of purchases at farmers' markets, by implementing the expectile estimator. Indeed, focusing on the tails, this econometric approach allows us to analyze phenomena that describe small market segments, like the one investigated here. Moving from low to high frequency of purchases (i.e., from low to high expectiles), the link among the variables of the model could change. Their impact may worsen/improve when moving from low to high purchase frequency. Thus, the association between values, attitudes, and purchase frequency would change depending upon the level of the dependent variable. With respect to other estimation approaches, the expectiles allow the pattern of the estimated coefficients to be revealed as the purchase frequency changes.

The paper is structured as follows. The "Literature review" section reviews the literature, and the "Theoretical framework" section defines attitudes and values and sketches the hypotheses under investigation. "The estimation approach" section summarizes the statistical methods implemented, and the "Questionnaire and data" section describes the data set. The results are reported in the "Results" section and commented in the "Discussion and conclusion" section, while the last section looks ahead to future research and further developments.

\section{Literature review}

The role played by attitudes and values in participation in farmers' markets has been widely investigated. Gilg and Battershill (1998), in one of the early papers on this topic, suggested that the increasing dissatisfaction of consumers with industrialized food markets, characterized by standardized products with high environmental impact, led them 
toward FMs. In an ethnographic fieldwork study based on two farmers' markets in the San Francisco Bay, Alkon (2008) suggests that FM purchases are influenced by the consumers' desire to lessen the ecological costs of food production and to sustain small rather than large farms out of a sense of social justice. By contrast, Conner et al. (2010), investigating a representative sample of Michigan residents, found that supporting local farms, product quality and food safety are the most important factors in the decision whether or not to shop at FMs. Feagan and Morris (2009) decomposed the concept of embeddedness into social (social interaction, knowledge of vendors, etc.), spatial (food freshness, supporting the local), and natural (environmentally friendly production, carbon footprint, etc.) and considered these factors the main motivations for participating in FMs. Lombardi et al. (2015) found among participants in an Italian Solidarity Purchasing Group, a particular form of farmers' market, a substantial presence of benevolence and universalism, values measured through the Schwartz human values (Migliore et al. 2012; Migliore et al. 2015). In a study also conducted on an Italian Solidarity Purchasing group, Cembalo et al. (2015) found a general aversion towards technology and modernity among participants. Lastly, Feldmann and Hamm (2015) analyzed 73 papers related to preferences for local food and concluded that "the most frequently named attitudes that result in local food purchases were related to product quality (i.e. freshness and taste), consumers' personal health, food safety, care for the environment, and support of the local economy" (ibidem, p. 157).

Summarizing, it seems that the recent literature suggests, in a broad sense, that the purchase of food products at farmers' markets is linked, on the one hand, to personal values and ethical beliefs and, on the other, to aversion towards the mainstream food system.

In this context, we test the existence of a hierarchical relationship between values and purchase frequency at FMs, with attitudes to the environment and mainstream food system as mediators. By introducing the model, this study sheds light on how a consumer's behavior, such as buying at farmers' markets, can be driven by more abstract notions (human values) and specific reactions to the modern food system (attitude toward the environment and toward industrialized food markets). Human values are recognized throughout all major cultures and are difficult to change. Values and their influence on individual attitudes and behavior can help us to better understand how the behavior of consumers vis-à-vis FMs is affected by their own inner values and attitudes toward the environment and the industrialized food sector (Vega-Zamora et al., 2020).

Homer and Kahle (1988) in a seminal paper suggested the existence of a hierarchical relationship between abstract human values, attitudes, and behavior. The theoretical model assumes a flow from more abstract cognitions to mid-range cognitions to a specific behavior. While attitudes refer to the degree to which a person has a favorable or unfavorable evaluation of a specific behavior (Ajzen and Driver 1992), human values are "...enduring beliefs that a specific mode of conduct or end-state of existence is personally or socially preferable to an opposite or converse mode of conduct or end-state of existence" (Rokeach 1973, p. 5). Actually, the link between values and attitudes is considered stable over time, while the link between attitudes and specific behavior is more volatile and can change depending on the circumstances (Hayley et al. 2015). It should also be stressed that any attitude or behavior can involve one or more values (Schwartz 2012). 
Homer and Kahle's cognitive hierarchy model (CHM) has often been applied to explain specific behaviors. Grunert and Juhl (1995), in a study based on 174 interviews with Danish teachers, show the presence of a hierarchical link between values (universalism, benevolence, and openness to change), environmental attitudes, and purchases of organic foods. McFarlane and Boxall (2000) found, among campers and hunters in Canada, a hierarchical link among biocentric values, positive attitudes toward forest protection-oriented management strategies, and purchasing behavior. Milfont et al. (2010), through a questionnaire submitted to 684 undergraduates from three countries (Brazil, New Zealand, and South Africa), demonstrated the hierarchical linkage between biospheric values, environmental attitudes, and eight specific ecological behaviors. Lastly, Hayley et al. (2015) in research based on 202 Australian consumers found that the CHM supports the hierarchical relationship between universalism, attitudes towards reducing meat consumption, and less frequent consumption of meat and fish.

\section{Theoretical framework}

In this study, we predict a hierarchical relationship between values, attitudes, and frequency of buying at farmers' markets, where attitudes play a key role as mediators between values and behavior. The theoretical framework is illustrated in Fig. 1.

\section{The dependent variable}

The dependent variable is given by the frequency of buying at farmers' markets, as measured by eight behavioral categories: (a) never, (b) less than once a month, (c) once a month, (d) two or three times a month, (e) once a week, and (f) more than once a week. This approach follows that suggested by Grunert and Juhl (1995) for investigating the relationship between values, environmental attitudes, and the purchase of organic foods.

\section{Buying at farmers' markets and consumer attitudes}

The two attitudinal scales used in this research are shown in Table 1. Krystallis et al. (2009) suggested both scales to investigate the attitudes of European citizens from four countries (Belgium, Denmark, Poland, and Germany) towards pig production systems. Both scales exhibit stability and cross-cultural validity in the European context (Krystallis et al. 2009). The attitudinal scale towards environment and nature is a reduced version of the New Environmental Paradigm (Dunlap et al. 2000). It is a five-item scale

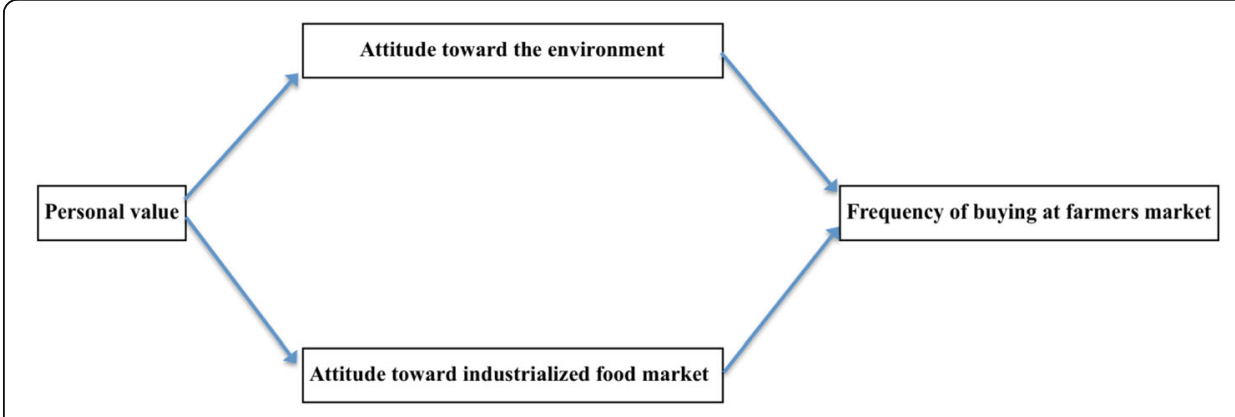

Fig. 1 The conceptual model 
Table 1 Attitudinal scales

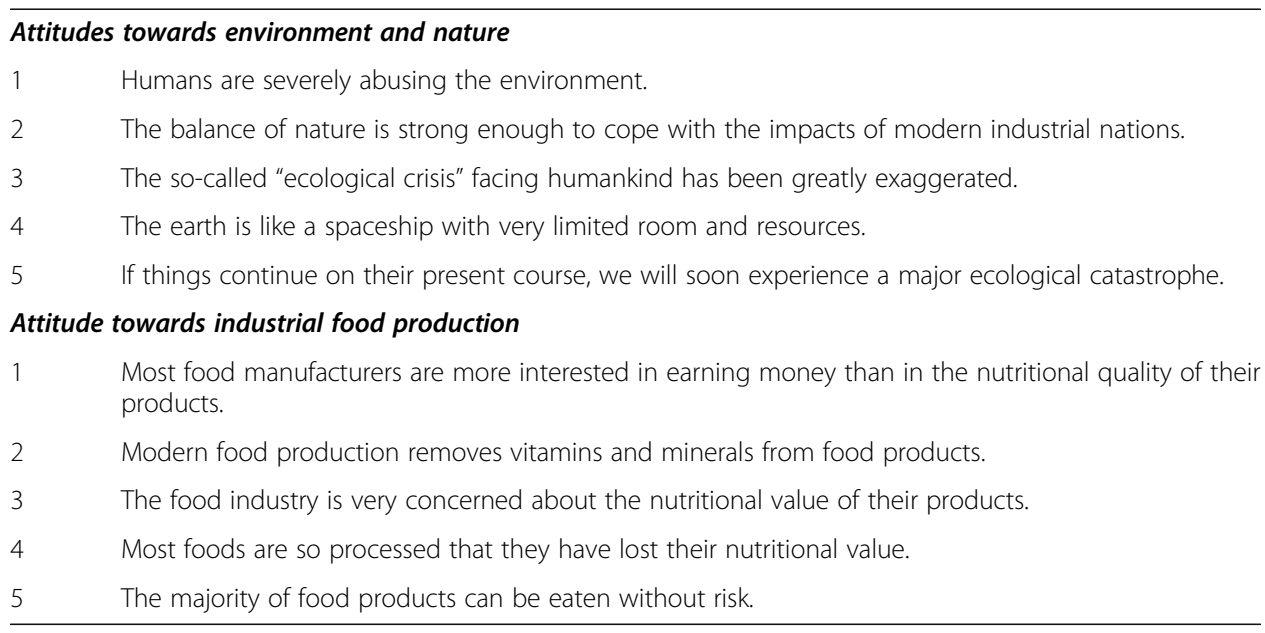

where items are measured on a seven-point interval rating scale, the lowest score indicating "strongly disagree" while the highest score "strongly agree." For example, one item is: "If things continue on their present course, we will soon experience a major ecological catastrophe."

The second scale measures the attitude towards industrial food production. It is a five-item scale where items are measured on a seven-point interval rating scale, the lowest score being tantamount to "strongly disagree" while the highest to "strongly agree." For example, one item is: "Most foods are so processed that they have lost their nutritional value."

\section{Personal values}

Over the last 50 years, various scales for measuring human values have been suggested (Rokeach 1967 and 1973; Inglehart 1971; Lonner et al. 1980; Schwartz 1992). In the present paper, the approach proposed by Schwartz (1992) was adopted. According to Schwartz (2012), human values have six main features: values are beliefs, values refer to desirable goals, values transcend specific actions and situations, values serve as standard criteria, values are ordered by importance, and the relative importance of multiple values guides action. The value constructs are measured through a questionnaire translated and administered in more than 50 languages and applied in different contexts, demonstrating that the taxonomy of values suggested by this author is close to universal (Verkasalo et al. 2009). Schwartz (2012) considers values as "desirable, transsituational goals, varying in importance, that serve as guiding principles in people's lives" (p. 267). According to this theory, there are 10 basic human values springing from three universal requirements of the human condition: (a) needs of individuals as biological organisms, (b) requisites of coordinated social interaction, and (c) survival and welfare needs of groups (p. 267). The ten basic human values are (1) self-direction, (2) stimulation, (3) hedonism, (4) achievement, (5) power, (6) security, (7) conformity, (8) tradition, (9) universalism, and (10) benevolence.

The above values can be organized in a circular manner: the closer the values are inside the circle, the more similar the motivations of the two values; the further away 
values are within the circle, the more dissimilar are the motivations behind them (see Fig. 2). The 10 values suggested by Schwartz can, in turn, be grouped into four opposite meta-values: openness to change (stimulation, self-direction, and hedonism) versus conservation (security, conformity, and tradition) and self-transcendence (benevolence and universalism) versus self-enhancement (hedonism, achievement, and power). Hedonism can belong either to the meta-value openness to change or to the meta-value self-enhancement, which is why some authors suggest that the Schwartz meta-values are $4+$ 1, with hedonism standing alone (Caracciolo et al. 2016).

In detail:

- Self-transcendence is centered on the well-being of people and nature or the wellbeing of those with whom one is in personal contact;

- Openness to change emphasizes independent thoughts and actions and the desire to lead a challenging life;

- Conservation: respondents scoring highly in this meta-value consider the following to be important: preservation of the past, resistance to change, and respect for social norms;

- Self-enhancement emphasizes social status and prestige and dominance over people and resources.

It is important to note that there are two approaches to measure Schwartz values: the Schwartz value survey (Schwartz 1992) and the Portrait Value Questionnaire (PVQ) (Schwartz et al. 2001). The first consists of 57 questions, while the second is based on 21 short verbal portraits. The choice between the two methods depends on the research focus. However, the PVQ is easier to implement, allows reliable results (Schwartz et al. 2001), and is a convenient measure for value comparison (Lindeman and Verkasalo 2005). In this study, we used the PVQ approach. In detail, each of the 21 short verbal portraits describes a person's goals and aspirations related to a specific value. For

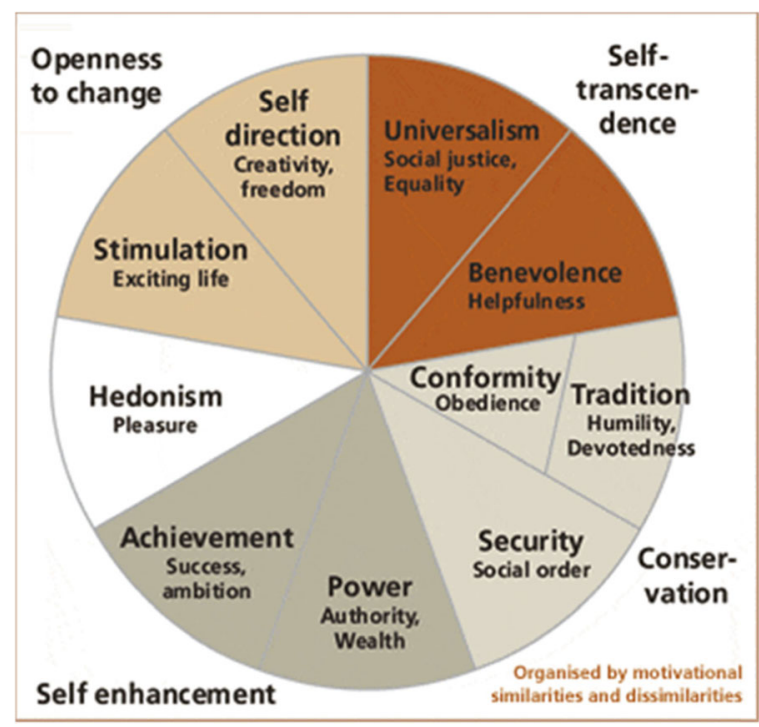

Fig. 2 Theoretical model of relations among ten motivational values 
example, the following portrait is related to universalism: "I think it is important that every person in the world be treated equally. I want justice for everybody, even for people I do not know." The answer is anchored on a Likert scale ranging from 1 (meaning "very similar to me") to 6 (meaning "very different from me").

It has been widely shown that the Schwartz values and meta-values reinforce the mediating role of attitudes between values and behavior. Schultz and Zelezny (1999) found a positive relationship between self-transcendence and pro-environmental attitudes measured through the New Environmental Paradigm (Dunlap et al. 2000), and a negative one with conservation. By contrast, Hayley et al. (2015) found that universalism predicted positive attitudes towards reducing consumption of red meat. According to Dreezens et al. (2005), respondents with a high score for universalism have a positive attitude toward organic food and a negative attitude toward genetically modified food; the opposite occurs for respondents with a high score for power. A relationship between Schwartz values and attitude has also been proven with respect to political attitudes (Cohrs et al. 2005; Rathbun et al. 2016).

\section{Hypotheses}

The theoretical framework depicted in Fig. 1 is tested according to the following five hypotheses:

Hypothesis 1: The higher the positive attitude towards environment and nature, the higher is the frequency of buying at farmers' markets.

Hypothesis 2: The higher the negative attitude towards industrial food production, the higher is the frequency of buying at farmers' markets.

Hypothesis 3: There is a positive relationship between self-transcendence and proenvironmental attitude.

Hypothesis 4: There is a negative relationship between conservation and proenvironmental attitude.

Hypothesis 5: There is a negative relationship between conservation and attitude toward industrialized food markets.

Hypotheses $\mathrm{H} 1$ and $\mathrm{H} 2$ have been suggested by several authors (Alkon 2008; Feldmann and Hamm 2015), while Schultz and Zelezny (1999) confirmed H3 and H4 in a study on 14 countries from Latin America, Spain, and the USA. H5 was first suggested by Botonaki and Mattas (2010) who found conservation to be related to a negative attitude toward convenience food and to a positive attitude toward variety in diet, involvement with food, and caring for food with natural content and sensory appeal. In this study, we adopted the broader hypothesis that conservation is related to a negative attitude toward industrialized food.

Most of the studies investigating factors related to purchases at FMs are based on case studies involving one or few local FMs, or at most a single region/state. This study, to our knowledge, is the first to be based on a representative sample of consumers in a European country. Data on purchasing frequency at FMs and on attitudes and values were collected through a questionnaire submitted to a representative sample of 1009 German consumers. 


\section{The estimation approach}

The above stylized facts are investigated using a regression model. Attitude towards the environment and, in turn, towards industrialized food are the determinants of purchase frequency at farmers' markets. The model was estimated by two-stage least squares (2SLS) to reproduce the hierarchical links between values and attitudes. The first stage considers attitudes as a function of values-conservation and self-transcendence-while the second stage considers the link between the frequency of purchases at farmers' markets and attitudes. This means computing the coefficients of the CHM at the conditional mean of purchase frequency at farmers' markets. In addition, the following sections compute the $\mathrm{CHM}$ also at low/high values of the dependent variable, for rare/frequent buyers at FMs. The regression coefficients may assume different values depending on the level of the dependent variable, namely, the frequency of purchases at FMs.

Focus on a possibly changing pattern of the CHM estimated coefficients leads to the selection of a regression model instead of the more frequently implemented SEM approach. The latter would not reveal a changing pattern of the regression coefficients. In contrast, the approach considered here allows us to reveal such a pattern and provides in-depth knowledge of the determinants of purchases at FMs at various frequencies.

The presence of changing coefficients can be assessed by implementing the expectile estimator (Newey and Powell 1987; Schnabel and Eilers 2009; Sobotka et al. 2013) which computes a regression at different locations. It is defined as a weighted least squares estimator: an asymmetric weighting system is introduced to move the estimated model away from the conditional mean of the dependent variable, as provided by the least squares estimator. The expectile allows us to compute the regression parameters in the tails of the conditional distribution of the dependent variable, thus revealing the impact of the explanatory variables at its lower/higher values, for rare/ regular buyers. We can then explore whether the estimated coefficients of the model differ along the conditional distribution of the dependent variable: the center, the upper, or the lower tail. At the lower/upper tail, the link between the dependent and the explanatory variables may diverge from the relationship estimated at the center. An estimated coefficient may even assume opposite signs in the tails. To the best of our knowledge, there have been no other attempts to compute the CHM both on average and in the tails, for different levels of the dependent variable.

Analysis in the tails may be used to examine small market segments in a representative sample instead of a convenience sample, which is generally considered when investigating small market segments.

Furthermore, expectiles are usually implemented in the simple regression framework, while in the following sections, the expectiles are instead estimated in a simultaneous equation model: the 2SLS estimated model is moved to the left/right tail by means of an asymmetric weighting system. As mentioned above, the results could change along the conditional distribution: for instance, frequent buyers could have a stronger/weaker aversion to industrialized food, while the pro-environmental attitude could increase/decrease with the frequency of purchases.

The expectile estimator, being defined as an OLS regression shifted away from the conditional mean, toward the tails, shares with OLS its lack of robustness. To check the robustness of the results supplied by the expectiles, an additional estimator, the 
mode regression (Shuong and Zhang 2001), is implemented. The mode is a measure of location which is particularly useful in the case of asymmetric distributions. It belongs to the class of robust estimators since it computes the regression passing through the conditional mode, which is the most frequent value of the dependent variable conditional on the explanatory variables, i.e., the bulk of data. It can be expressed as a weighted least squares estimator as well (see the Appendix for details) and provides an additional measure of central tendency with the twofold goal of attaining further knowledge of the behavior of the model while providing robust results.

\section{Questionnaire and data}

This research was based on data collected through a questionnaire administered by GfK Eurisko, submitted to a representative, stratified sample of 1009 German consumers. Those interviewed were responsible for major food purchasing decisions in each household. ${ }^{1}$

Table 2 shows quite a balanced sample with respect to gender. As for income distribution, there is a preponderance of moderate-income individuals and quite a large percentage of non-responses. In terms of education, those with university degrees formed a large percentage.

The first part of the questionnaire dealt with consumer food purchasing behavior. This section posed questions concerning consumers' frequency of buying at different retail channels. After a brief introduction on the different retail channels, the following critical question is posed: "When you buy food how often do you buy at the following sales locations?". Five alternatives were given: (1) grocery stores, (2) supermarkets, (3) discounts, (4) district markets, and (5) farmers' markets ${ }^{2}$. For each retail channel, six alternative responses are available: (1) never, (2) seldom, (3) once a month, (4) two or three times a month, (5) once a week, and (6) more than once a week.

Table 3 shows that supermarkets are the most commonly frequented stores for grocery purchases, followed by discounts. It may be noted that more than half of consumers attend farmers' markets to buy food. Regular visitors (answers "once a week" and "more than once a week") number slightly above $10 \%$.

Focusing on purchases at farmers' markets occurring once a month or more, buyers are mostly without children (67.4\%), in a two- or three-person household (34.1\% and $28 \%$, respectively), and aged from 30 to 50 (37\%).

The second part of the questionnaire focused on consumer attitudes. This part contains two 5-item scales designed to measure attitudes towards the environment and nature (nature) and towards industrial food production (foodindustry). In particular, the variable nature is the linear combination of five different items, some with positive and others with a negative content. Points 2 and 3 in the top section of Table 4, due to their pessimistic attitude toward the environment, were reversed before entering the definition of nature. Cronbach's alpha coefficient for this scale is equal to 0.85 , thus showing good reliability.

\footnotetext{
${ }^{1}$ An on-line panel sample was selected, and the sample was stratified by geographical area, city size, gender, and age.

${ }^{2}$ Respondents were provided with the following definition of farmers' market: "Farmers' markets are places where a group of farmers come together, usually once a week, to sell their products."
} 
Table 2 Socio-demographic characteristics of the sample

\begin{tabular}{|c|c|}
\hline \multicolumn{2}{|l|}{ Gender (\%) } \\
\hline Male & 33.0 \\
\hline Female & 67.0 \\
\hline Age(years): mean & 47 \\
\hline \multicolumn{2}{|c|}{ Children $<10$ years old $(\%)$} \\
\hline Yes & 16.4 \\
\hline No & 83.6 \\
\hline \multicolumn{2}{|c|}{ Economic situation of the household } \\
\hline Poor & 23.5 \\
\hline Moderate & 39.3 \\
\hline Good & 23.3 \\
\hline No answer & 13.9 \\
\hline \multicolumn{2}{|c|}{ Highest qualification completed (\%) } \\
\hline$<$ High School & 11.8 \\
\hline High School & 22.5 \\
\hline University Degree & 28.9 \\
\hline Sample Size & 1.009 \\
\hline
\end{tabular}

Foodindustry is the linear combination of five other items, reported in the bottom section of Table 4 on attitudes. Points 3 and 5 in Table 4 have a positive content due to their optimistic attitude towards industrial food and were reversed before entering the definition of foodindustry. Cronbach's alpha is slightly smaller (0.70), assuring consistency.

In the third part of the questionnaire, each of the ten human values suggested by Schwartz is measured through the 21-item Portrait Value Questionnaire. Table 5 reports sample means and standard deviations of the two meta-values, self-transcendence and conservation, used to formulate H3, H4, and H5. Cronbach's alpha coefficient is

Table 3 Percentages of the frequency of buying food at different sales locations

\begin{tabular}{lcccccc}
\hline \multicolumn{7}{c}{$\begin{array}{c}\text { Frequeny of buying } \\
\text { (percentage in parenthesis) }\end{array}$} \\
\cline { 2 - 6 } & never & seldom & once month & $\begin{array}{c}\text { 2o } 3 \text { times } \\
\text { month }\end{array}$ & once a week & $>1$ a week \\
Grocery stores & $240(27.7)$ & $324(32.8)$ & $91(9)$ & $132(13)$ & $143(14.2)$ & $79(7.8)$ \\
Supermarket & $29(2.8)$ & $58(5.7)$ & $59(5.9)$ & $156(15.4)$ & $431(42.7)$ & $276(27.3)$ \\
Discount & $64(6.3)$ & $98(9.7)$ & $58(5.7)$ & $139(13.7)$ & $422(41.8)$ & $228(22.6)$ \\
District market & $194(19.2)$ & $293(29.0)$ & $117(11.6)$ & $115(11.4)$ & $232(22.9)$ & $58(5.7)$ \\
Farmers market & $429(42.5)$ & $328(32.5)$ & $70(6.9)$ & $64(6.3)$ & $80(7.9)$ & $38(3.8)$ \\
\hline
\end{tabular}


Table 4 Attitude scales

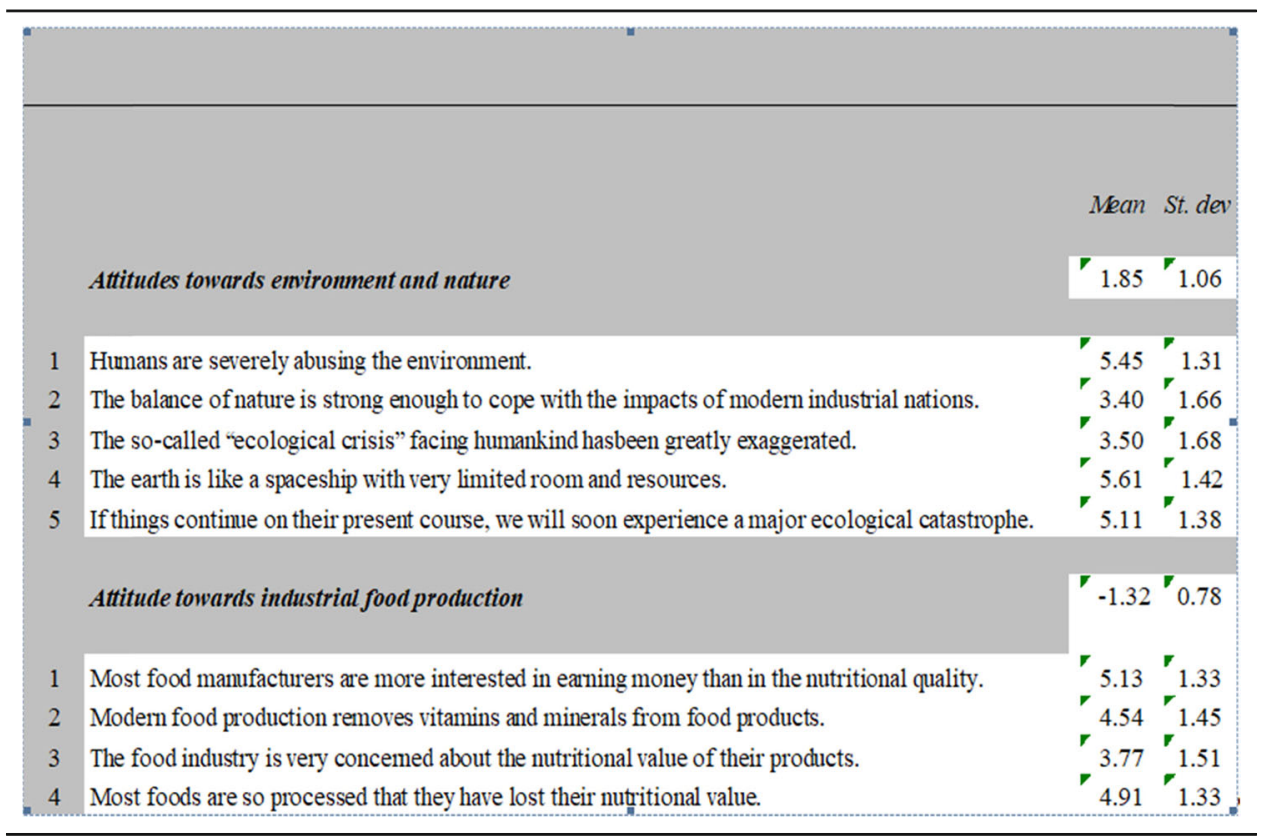

equal to 0.93 for self-transcendence and 0.89 for conservation, thus showing good reliability. Finally, the last part of the questionnaire deals with the consumer's sociodemographic profile.

\section{Results}

The results of the econometric model in Table 6 show that frequent buyers at farmers' markets have a stronger aversion to industrialized food and that the attitude towards the environment increases with the frequency of purchases.

The dependent variable farmers' markets, which considers the frequency of purchases at FMs, is related to the attitudinal explanatory variable nature and, in turn, to foodindustry. The selected estimator is a two-stage least squares (2SLS) where the values conservation and self-transcendence explain the attitudes nature and foodindustry in the first stage; next, the fitted values of the first stage, $x_{i}$, explain the frequency of buying at FMs. Conservation is defined as the linear combination of security, tradition, and conformity, while self-transcendence is the combination of universalism and benevolence. The internal consistency of the scales as evaluated by Cronbach's alpha is reported in the first column of Table 5 .

In a sample of size $n=1009$, 2SLS regression computes how an average frequency of purchases at farmers' markets, $y_{i}$, is influenced by attitudes towards nature and foodindustry, $x_{i}$, which are, in turn, explained by conservation and self-transcendence. ${ }^{3}$ Table 6 reports the results for the simultaneous equation model:

\footnotetext{
${ }^{3} \mathrm{~A}$ check on the validity of 2 SLS is provided by a simple OLS regression where the dependent variable farmers' market is a direct function of the meta-values conservation and self-transcendence, excluding attitudes, but in this model, the coefficients are not statistically different from 0: farmers market $=$

$1.33+0.08$ conservation $\quad 0.09$ self - trascendence

(5.65) (1.44) (1.53)
} 
Table 5 Values

\begin{tabular}{|c|c|c|c|c|c|c|}
\hline Values & & C. alpha & & Mean & & St. dev \\
\hline Self-transcendence & $\boldsymbol{r}$ & 0.93 & $r$ & 9.93 & $\boldsymbol{r}$ & 2.07 \\
\hline Benevolence & $r$ & 0.91 & $\boldsymbol{r}$ & 5.21 & $r$ & 1.19 \\
\hline Universalism & $r$ & 0.82 & $r$ & 4.72 & $r$ & 1.09 \\
\hline Conservation & $r$ & 0.89 & 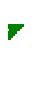 & 14.32 & $r$ & 3.12 \\
\hline Security & 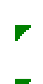 & 0.90 & $\Gamma$ & 5.12 & $r$ & 1.27 \\
\hline Tradition & 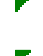 & 0.83 & $\tau$ & 4.57 & $\pi$ & 1.26 \\
\hline Conformity & $V$ & 0.86 & 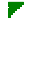 & 4.63 & $V$ & 1.23 \\
\hline
\end{tabular}

$$
\begin{aligned}
& y_{i}=\alpha+\beta_{i} x_{i}+u_{i} \\
& x_{i}=\gamma_{0}+\gamma_{1} \text { conservation }_{i}+\gamma_{2} \text { self }- \text { transcendence }_{i}
\end{aligned}
$$

The frequency of purchases at farmers' markets is negatively related to the attitude toward foodindustry, as claimed in $\mathrm{H} 2$, and positively related to attitude towards the environment, nature, as stated in H1. Meanwhile, conservation is negative in explaining foodindustry, and $\mathrm{H} 5$ is validated, but it is positive and statistically significant in explaining nature, as opposed to what is suggested by H4. Self-transcendence yields large $t$-statistics in both equations and has a positive impact in explaining nature, as in $\mathrm{H} 3$, while the sign of this coefficient is negative when explaining foodindustry.

Summarizing, this model validates hypotheses H1, H2, H3, and H5: Self-transcendence has a positive impact on pro-environmental attitude, nature. Nature, in turn, has a direct impact on purchases at farmers' markets. Self-transcendence and conservation have a negative impact on foodindustry which, in turn, negatively affects FM purchases.

The last column of Table 6 reports the coefficients computed by a comparable SEM model. These results are similar to the 2SLS approach of the first column. The advantage of 2SLS is that, through the expectiles, it is possible to look at the behavior of the model in the tails, for rare and frequent buyers. Conversely, expectiles cannot be implemented in the SEM framework.

Through the expectiles, the selected model can be estimated at the lower and upper tail, away from the center of the distribution. The second column of Table 6 provides the estimates of the model at the 25th expectile, in the left tail, while the second to the last column of this table reports the results at the 75th expectile.

The link between foodindustry and farmers' markets is lower when moving from the left to the right tail, with the slope coefficient assuming values $-0.31,-0.40$, and -0.48 respectively at the 25 th, at the mean/50th, and at the 75th expectiles. Vice versa, the link between nature and farmers' markets increases particularly in the right tail, rising from 0.33 at the 25th expectile to 0.42 at the mean/50th and to 0.48 at the top expectile. People buying often at FMs are more averse to industrialized food compared to 


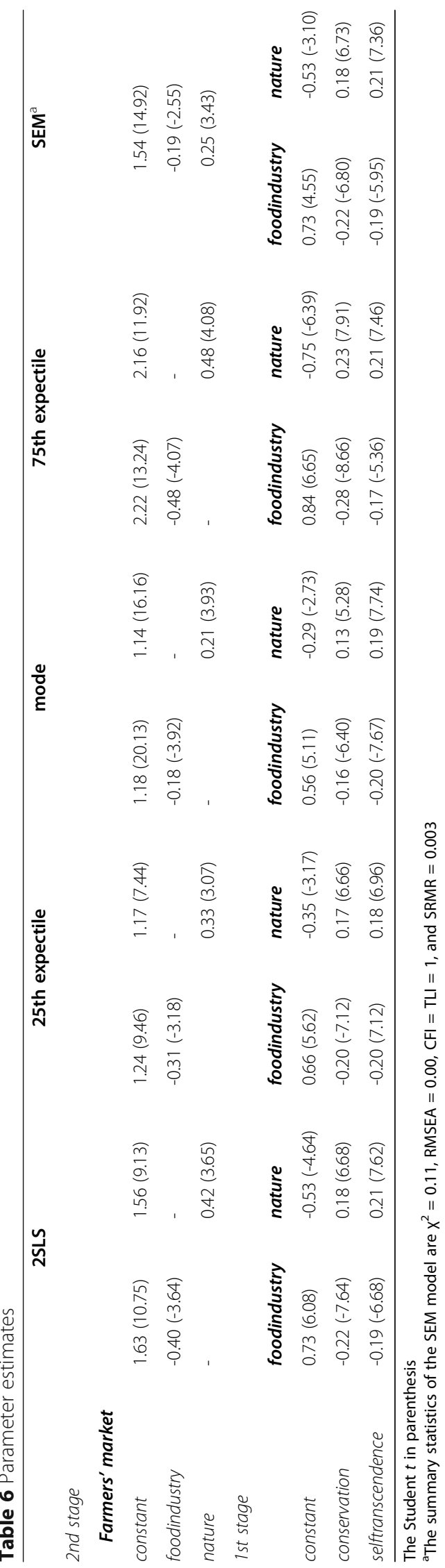


people buying there less frequently. People buying regularly at FMs have a larger proenvironmental coefficient than those who rarely do so.

Looking at the behavior of the first-stage equations in the tails, conservation is negative and its impact on foodindustry worsens across expectiles, while it has a positive impact on nature, which increases across expectiles. The negative impact of self-transcendence on foodindustry becomes milder at the higher expectile, while its positive impact on nature is stable from the mean onward.

Besides the 25th, 50th, and 75th expectiles, it is possible to select any value between 0 and 1 for the location of the estimated line. In particular, noting that in Table 3 people not buying at farmers' markets are modal, accounting for $42.5 \%$ of responses, the 42.5th expectile can be computed. This entails estimating the model for all those customers never buying at farmers' markets. The 42.5th expectile coefficients assume intermediate values between the 25th and 50th expectile estimates. Indeed, the impact of nature on farmers' markets is 0.40 and is statistically significant, $t=3.49$, while the impact of foodindustry is -0.37 with a Student $t$ of -3.48 . Although the 42.5 th expectile was selected by looking at the unconditional mode of the variable farmers' markets, these results do not coincide with the mode regression estimates. The mode regression (Kemp and Santos Silva 2012) is a semi-parametric estimator passing through the conditional mode, i.e., the high frequency values of the dependent variable conditional on the explanatory variables. Depending upon the value of the explanatory variable, the farmers' markets mode does not necessarily occur at the non-buyers' group. Figure 3 shows the unconditional density of farmers' markets in the left graphs and its conditional distributions, selecting, for instance, the values of nature in the interval 4.2-4.5 and nature $=5$ in the top right graphs, and of foodindustry $=3,4$ in the bottom right graphs. The graphs show how different unconditional and conditional distributions can be: at the selected values of the explanatory variables, the conditional distributions of farmers' markets are smoother, and the mode moves upward. The differences between unconditional and conditional distributions cause the discrepancy between the mode regression and the 42.5th expectile estimates, since the latter consider exclusively people never buying food at farmers' markets.

The estimated coefficients of the mode regression, reported in the third column of Table 6, when compared with the values provided by the 42.5 th expectile, are milder for the foodindustry coefficient, -0.18 with a Student $t$ of -3.92 , and smaller for $n a-$ ture, 0.21 with $t=3.93$. However, they show that the attitude toward environment and industrial food at the conditional mode is statistically significant, albeit smaller than the values computed by the expectile estimator. Besides the different definition of the two estimators, it is possible that the expectile results are somewhat inflated by the positive skewness of the farmers' market distribution. ${ }^{4}$

\section{Discussion and conclusion}

The increasing importance of short food supply chains (SFSCs) as a sustainable alternative to global markets (Renting et al. 2003; Giampietri et al. 2016) calls for a more specific analysis of the determinants of consumer participation in the new forms of distribution organizations (Shaw et al. 2005; Conner et al. 2010). Our study contributes to the increasing

${ }^{4}$ Details on the first-stage results for the 42.5 th expectile are available on request. 


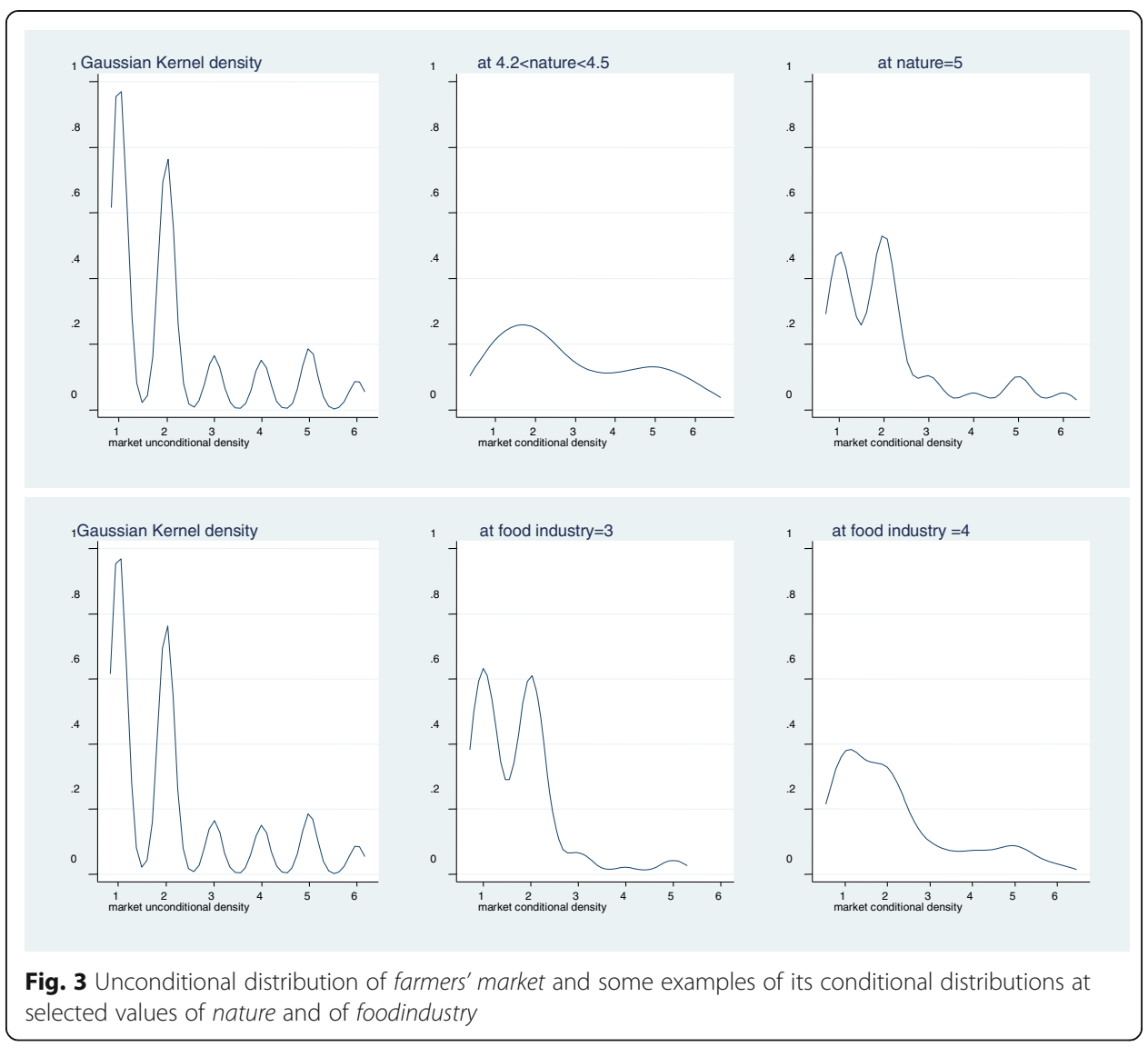

strand of the literature highlighting the deep-rooted factors driving consumers to choose sustainable and ethical expenditures (Vermeir and Verbeke 2006; Lindeman and Väänänen 2000; Botonaki and Mattas 2010; De Maya et al. 2011; Caracciolo et al. 2016) and implements an econometric approach that allows proper investigation of a representative national sample instead of a convenience sample, as traditionally done. In a broader sense, it contributes to better understand shopping decisions thanks to a structured econometric analysis that generates results extendible to a larger population.

The aim of this study was to control for the existence of a hierarchical relationship among human values, as measured by the Schwartz values, attitudes toward industrialized food markets, attitudes toward the environment, and purchase frequency at farmers' markets in Germany. The analysis was carried out at national level, using a representative sample of the German population.

An econometric model was implemented to analyze behaviors of small-size market segments using a representative sample instead of a convenience one. The hierarchical relationship among human values, attitudes, and frequency of purchases was investigated using a two-stage least squares (2SLS) approach. The 2SLS coefficients of the CHM were computed, on average, for the mean frequency of purchases at farmers' markets. These results are consistent with those provided by SEM, which is the approach generally implemented in such models and which provides a check on the 2SLS estimates. With respect to SEM, the 2SLS has the advantage of allowing the analysis to move away from the conditional average frequency of purchases. The coefficients at 
low/high values of the dependent variable, rare/frequent buyers at farmers' markets, were analyzed by implementing the expectile estimator.

The results, computed at different frequencies of purchases at farmers' markets, show the influence of attitudes toward environment and nature (nature) and attitudes toward industrial food production (foodindustry) on buying at farmers' markets. In particular, the positive influence of nature and the negative impact of foodindustry on purchases at FMs validated H1, stating that the higher the positive attitude toward the environment, the higher the frequency of buying at FMs-together with $\mathrm{H} 2$, asserting that the higher the negative attitude towards industrial food production, the higher the frequency of buying at FMs. The link between foodindustry and farmers' markets worsens when moving from rare to frequent buyers. Vice versa, the link between nature and farmers' markets increases when moving to the 75th expectile. These results show that frequent purchasers at farmers' markets are more averse to foodindustry and have a larger nature coefficient compared to others.

The analysis in the tails, for low/high frequency of purchases, allows small market segments to be evaluated. To the best of our knowledge, there has been no other attempt to compute the CHM either on average or in the tails, for different levels of the dependent variable, or to analyze these relationships in a representative sample instead of a convenience sample.

This model also verifies $\mathrm{H} 3$. Indeed, self-transcendence has a positive impact on proenvironmental attitude, nature, while $\mathrm{H} 4$ is not validated by the first stage results. $\mathrm{H} 5$ is confirmed as well, since the coefficient relating conservation to foodindustry is negative and statistically significant. In addition, conservation has a positive impact on $n a-$ ture across expectiles; self-transcendence negatively affects foodindustry, while it has a positive impact on nature which appears stable at and above the mean.

The above-mentioned results support the CHM model proposed by Homer and Kahle (1988), showing that personal values and attitudes are key variables in predicting ethically oriented lifestyle choices (Grunert and Juhl 1995; Milfont et al. 2010).

Summarizing, our results suggest the existence of a hierarchical relationship among human values as measured by the Schwartz values, attitude toward industrialized food markets, attitude toward the environment, and the frequency of purchases at farmers' markets. In addition, they highlight the different strengths of these links when moving from rare to frequent buyers. This heterogeneity in the hierarchical relationship is clearer between behavior and attitudes. The results show that the difference in values and attitudes can explain differences in the consumers' choice of the distribution channel. The estimated links conservation-self-transcendence-nature-farmers' markets and conservation-self-transcendence-foodindustry-farmers' markets at different expectiles could represent an efficient approach to consumer segmentation.

The contribution of this paper to the existing literature is twofold:

i) The selected approach computes the links among values-attitudes-behavior not only on average by the standard 2SLS estimator, but also for rare and frequent buyers, away from the average values as provided by a two-stage expectile estimator, and by a robust estimator which computes the conditional mode regression

ii) The percentage of observations in the tails is generally lower than at the average. Therefore, the standard approach to estimate a model in small subsets is to 
consider convenience samples; by contrast, expectiles make it possible to investigate small market segments in a representative sample

Farmers' markets and, in general, SSC represent a potentially profitable opportunity for farms in large European areas. New forms of distribution can be successfully exploited and scholars, policymakers, public administrators, and marketers need to know how to effectively analyze and appropriately segment consumers.

\section{Limitations and future research}

A limitation of this study is that it relies on the use of self-reported behavior, where consumers state their participation in farmers' markets. Our analysis concerned behavior regarding ethical issues, and self-reported information such as buying frequency could be affected by social desirability. It should also be pointed out that the hierarchical models implemented and verified in the study do not include other cognitive and situational variables that shape consumer participation in SSC.

The outcomes of this study suggest at least two directions for future research. First, the effect of conservation and self-transcendence on nature and foodindustry requires further analysis to better understand the role of values in the tails. Our results show, for instance, that the negative impact of self-transcendence on foodindustry became milder at the higher expectile. Secondly, future analysis should focus on different food channels to compare different values and attitudes involved. This could lead to better consumer segmentation and better marketing strategies.

\section{Appendix}

\section{Expectiles}

To move away from the center, the expectile estimator modifies the least squares objective function. An asymmetric weighting system $w_{i}$ moves the estimated line to the right or left tail of the conditional distribution of the dependent variable. Consider as the starting point the simple linear regression model $\mathrm{y}_{\mathrm{i}}=\alpha+\beta \mathrm{x}_{\mathrm{i}}+\mathrm{e}_{\mathrm{i}}$, with $y_{i}$ being the frequency of purchases and $x_{i}$ the attitudinal variable toward nature or, in turn, toward industrial food. The least squares estimator (OLS) minimizes the sum of the squared errors, $\Sigma_{i} e_{i}^{2}=\Sigma_{i}\left(y_{i}\right.$ $\left.-\alpha-\beta x_{i}\right)^{2}$, while the expectile objective function considers the weighted sum of squared errors, $\Sigma_{i} w_{i} e_{i}^{2}=\Sigma_{i} w_{i}\left(y_{i}-\alpha-\beta x_{i}\right)^{2}$. The asymmetric weights move the estimated regression toward the tails and away from the center. They are defined as follows:

$$
\mathrm{w}_{\mathrm{i}}=\theta \quad \text { if } \quad \mathrm{e}_{\mathrm{i}}>0
$$

\section{$1-\theta$ otherwise}

For instance, to compute the $\theta=25$ th expectile, which estimates the model when purchases at farmers' markets are rare, $w_{i}$ assigns weights $w_{i}=1-\theta=0.75$ to those observations below the OLS regression, in order to attract the estimated line toward the lower tail, while it assigns weights $w_{i}=\theta=0.25$ to the observations above the line. The larger weight attributed to the lower observations attracts the estimated line toward the left tail. Vice versa at the 75th expectile, for regular buyers at farmers' markets, $w_{i}=1-\theta=0.25$ for the observations below the OLS regression and $w_{i}=\theta=0.75$ for the observations 
above it in order to attract the estimated line toward the right tail. This provides an analysis of the model when purchases at farmers' markets are very frequent.

The estimating procedure of the expectile approach iterates between weights and regression coefficients. Convergence is reached after very few iterations.

However, the selected model is not estimated by the simple OLS regression but by 2SLS, due to the presence of the right-hand side endogenous variable $x_{i}$, which in our model is attitude toward the environment and toward industrialized food. Indeed, the hierarchical link relating values to attitudes may cause a correlation between attitude toward nature/industrialized food and the error term $e_{i}$. If this link is not taken into account, the estimates are inconsistent. In 2SLS, the attitude variable $x_{i}$ is replaced by its fitted value ${ }_{i}$ as computed in the first stage regression, where nature/industrialized food is related to self-transcendence and conservation. Thus, the first stage equation is

$$
x_{i}=\gamma_{0}+\gamma_{1} \text { conservation }_{i}+\gamma_{2} \text { self-transcendence } e_{i}+\varepsilon_{i}
$$

where $x_{i}$ represents, in turn, attitude toward nature or toward industrialized food. In the second stage, the model becomes

$$
y_{i}=\alpha+\beta_{i} \widehat{x_{i}}+u_{i}
$$

$y_{i}$ being the frequency of purchases at farmers' markets and $\mathrm{x}^{\wedge}{ }_{i}$ the instrumental variable, i.e., the fitted values computed in the first stage as $x^{\wedge}{ }_{i}=\gamma^{\wedge}{ }_{0}+\gamma^{\wedge}{ }_{1}$ conservation $_{i}$ $+{ }^{\wedge} \gamma_{2}$ self-transcendence $e_{i}$ to replace the observed $x_{i}$. Having estimated the model at the conditional mean, i.e., by 2 SLS, the asymmetric weighting system is introduced to investigate the behavior in the tails and a weighted 2SLS is implemented. The starting point is the standard 2SLS assigning unit weight to each observation. Then, the weights are computed as in (1). The first stage objective function becomes $\Sigma_{i} w_{i} \varepsilon_{i}^{2}=\Sigma_{i} w_{i}\left(x_{i}\right.$ $-\gamma_{0}+\gamma_{1}$ conservation $_{i}+\gamma_{2}$ self-transcendence $)^{2}$ and in the second stage it is $\Sigma_{i} w_{i} u_{i}^{2}=$ $\Sigma_{i} w_{i}\left(y_{i}-\alpha-\beta i^{\wedge} i\right)^{2}{ }_{i}$ represents the computed attitude toward nature and, in turn, toward industrialized food. Once again, few iterations suffice for convergence.

\section{Mode regression}

The mode regression can be defined as a weighted least squares estimator, with weights given by (Kemp and Santos Silva 2012)

$$
v_{i}=\exp \left[-u_{i}^{2} /\left(2 \delta^{2}\right)\right]
$$

and bandwidth parameter $\delta$ being a function of the median absolute deviation (MAD):

$$
\delta=.5 n-{ }^{1 / 7} \operatorname{MAD}\left(u_{i}\right)=.5 n-{ }^{1 / 7} \text { median }\left|u_{i}-\operatorname{median}\left(u_{i}\right)\right| .
$$

In this setting, the bandwidth defines the selected measure of central tendency. The authors show that for $\delta \rightarrow 0, v_{i}$ yields the mode regression while for $\delta \rightarrow \infty$ the above estimator coincides with OLS. Intermediate values of $\delta$ yield other robust regression estimators (M-estimators).

\footnotetext{
${ }^{5}$ The weights $v_{i}$ are obtained by selecting the Gaussian kernel function, $K\left(u_{i}\right)=\phi\left(u_{i}\right)$ where $\phi()$ is the standard normal density. However, the weighted least squares definition of the mode regression estimator holds for any kernel function based on $u_{i}^{2}$, and the functional form of the weights $v_{i}$ would change accordingly.
} 


\section{Abbreviations}

SSCs : Short supply chains; FMs : Farmers' markets; CHM : Cognitive hierarchy model; PVQ : Portrait Value Questionnaire; SEM: Structural equation modeling; 2SLS: Two-stage least squares

\section{Acknowledgements}

Acknowledgements are not applicable.

\section{Authors' contributions}

The authors equally contributed to the manuscript. The authors read and approved the final manuscript.

\section{Funding}

Funding is not applicable.

\section{Availability of data and materials}

Data are available on request.

\section{Competing interests}

None of the authors has competing interests.

Received: 30 January 2019 Revised: 23 July 2020

Accepted: 30 October 2020 Published online: 04 January 2021

\section{References}

Ajzen I, Driver BL (1992) Application of the theory of planned behavior to leisure choice. J Leis Res 24(3):207

Alkon AH (2008) From value to values: sustainable consumption at farmers markets. Agric Hum Values 25(4):487-498

Botonaki A, Mattas K (2010) Revealing the values behind convenience food consumption. Appetite 55(3):629-638

Caracciolo F, Cicia G, Del Giudice T, Cembalo L, Krystallis A, Grunert K, Lombardi P (2016) Human values and preferences for cleaner livestock production. J Clean Prod 112:121-130

Cembalo L, Lombardi A, Pascucci S, Dentoni D, Migliore G, Verneau F, Schifani G (2015) "Rationally local": consumer participation in alternative food chains. Agribusiness 31(3):330-352

Cohrs JC, Moschner B, Maes J, Kielmann S (2005) The motivational bases of right-wing authoritarianism and social dominance orientation: relations to values and attitudes in the aftermath of September 11, 2001. Pers Soc Psychol Bull 31(10):14251434

Conner D, Colasanti K, Ross RB, Smalley SB (2010) Locally grown foods and farmers markets: consumer attitudes and behaviors. Sustainability 2(3):742-756

D'Amico M, Di Vita G, Chinnici G, Pappalardo G, Pecorino B (2014) Short food supply chain and locally produced wines: factors affecting consumer behavior. Italian J Food Sci 26(3):329

De Maya SR, López-López I, Munuera UL (2011) Organic food consumption in Europe: international segmentation based on value system differences. Ecol Econ 70(10):1767-1775

Dreezens E, Martijn C, Tenbült P, Kok G, De Vries NK (2005) Food and values: an examination of values underlying attitudes toward genetically modified-and organically grown food products. Appetite 44(1):115-122

Dunlap RE, Van Liere KD, Mertig AG, Jones RE (2000) New trends in measuring environmental attitudes: measuring endorsement of the new ecological paradigm, a revised NEP scale. Aust J Soc Issues 56(3):425-442

Feagan RB, Morris D (2009) Consumer quest for embeddedness: a case study of the Brantford farmers' market. Int J Consum Stud 33(3):235-243

Feldmann C, Hamm U (2015) Consumers' perceptions and preferences for local food: a review. Food Qual Prefer 40:152-164

Gallenti G, Troiano S, Cosmina M, Marangon F (2016) Ethical and sustainable consumption in the italian coffe market: a choice experiment toanalyse consumers' willingness to pay. Ital Rev Agric Eco 71(2):153-76

Giampietri E, Finco A, Del Giudice T (2016) Exploring consumers' behavior towards short food supply chains. Br Food J 118(3): 618-631

Giampietri E, Verneau F, Del Giudice T, Carfora V, Finco A (2018) Telling the trust about consumers: a theory of planned behaviour perspective to investigate the role of trust in consumer purchasing decisions related to short food supply chains. Food Qual Prefer 64:160-6

Gilg AW, Battershill M (1998) Quality farm food in Europe: a possible alternative to the industrialized food market and to current Agri-environmental policies: lessons from France. Food Policy 23(1):25-40

Goodman D (2004) Rural Europe redux? Reflections on alternative agrofood networks and paradigm change. Sociol Rural 44(1):3-16

Grunert SC, Juhl HJ (1995) Values, environmental attitudes, and buying of organic foods. J Econ Psychol 16(1):39-62

Hayley A, Zinkiewicz L, Hardiman K (2015) Values, attitudes, and frequency of meat consumption. Predicting meat-reduced diet in Australians. Appetite 84:98-106

Hinrichs CC (2000) Embeddedness and local food systems: notes on two types of direct agricultural market. J Rural Stud 16(3):295-303

Homer PM, Kahle (1988) A structural equation test of the value-attitude-behavior hierarchy. J Pers Soc Psychol 54(4):638 Inglehart R (1971) The silent revolution in Europe: intergenerational change in post-industrial societies. Am Polit Sci Rev 65(04):991-1017

Irz X, Leroy P, Réquillart V, Solerb LG (2015) Farmers' markets and farm shops in Germany: is the motivation to buy there the same? In: 143rd joint EAAE/AAEA seminar, march 25-27, 2015. European Association of Agricultural Economists, Naples No. 202721

Kemp G, Santos Silva JM (2012) Regression towards the mode. J Econ 170:92-101

Krystallis A, de Barcellos MD, Kügler JO, Verbeke W, Grunert KG (2009) Attitudes of European citizens towards pig production systems. Livest Sci 126(1):46-56 
Lindeman M, Väänänen M (2000) Measurement of ethical food choice motives. Appetite 34(1):55-59

Lindeman M, Verkasalo M (2005) Measuring values with the short Schwartz's value survey. J Pers Assess 85(2):170-178

Lombardi A, Migliore G, Verneau F, Schifani G, Cembalo L (2015) Are "good guys" more likely to participate in local agriculture? Food Qual Prefer 45:158-165

Lonner WJ, Berry JW, Hofstede GH (1980) Culture's consequences: international differences in work-related values University of Illinois at Urbana-Champaign's Academy for Entrepreneurial Leadership Historical Research Reference in Entrepreneurship

Marsden T (1998) New rural territories: regulating the differentiated rural spaces. J Rural Stud 14(1):107-117

McEachern M, Seaman C, Padel S, Foster C (2005) Exploring the gap between attitudes and behaviour. Br Food J 107(8):60625

McFarlane BL, Boxall PC (2000) Factors influencing forest values and attitudes of two stakeholder groups: the case of the foothills model forest, Alberta, Canada. Soc Nat Resour 13(7):649-661

Mennella L (2019) II movimento slow food: Analisi socioeconomica di un fenomeno ecogastronomico in evoluzione (The slow food movement: socio-economic analysis of an evolving eco-gastronomy phenomenon) PhD thesis, University of Napoli Federico II

Migliore G, Cembalo L, Caracciolo F, Schifani G (2012) Organic consumption and consumer participation in food community networks. New Medit 11(4):46-48

Migliore G, Schifani G, Cembalo L (2015) Opening the black box of food quality in the short supply chain: effects of conventions of quality on consumer choice. Food Qual Prefer 39:141-146

Milfont TL, Duckitt J, Wagner C (2010) A crosscultural test of the value-attitude-behavior hierarchy. J Appl Soc Psychol 40(11):2791-2813

Newey W, Powell J (1987) Asymmetric least squares estimation and testing. Econometrica 55:819-847

Rathbun BC, Kertzer JD, Reifler J, Goren P, Scotto TJ (2016) Taking foreign policy personally: personal values and foreign policy attitudes. Int Stud Q 60(1):124-137

Renting H, Marsden TK, Banks J (2003) Understanding alternative food networks: exploring the role of short food supply chains in rural development. Environ Plan A 35(3):393-411

Rokeach M (1967) Value survey. Halgren Tests, Sunnyvale

Rokeach M (1973) The nature of human values. Vol. 438. Free press, New York

Roos G, Terragni L, Torjusen H (2007) The local in the global-creating ethical relations between producers and consumers. Anthropol Food S2

Schnabel SK, Eilers PHC (2009) Optimal expectile smoothing. Comput Stat Data Anal 53(12):4168-4177

Schultz PW, Zelezny L (1999) Values as predictors of environmental attitudes: evidence for consistency across 14 countries. $J$ Environ Psychol 19(3):255-265

Schwartz SH (1992) Universals in the content and structure of values: theoretical advances and empirical tests in 20 countries. Adv Exp Soc Psychol 25:1-65

Schwartz SH (2012) An overview of the Schwartz theory of basic values. Onl Read Psychol Culture 2(1):11

Schwartz SH, Melech G, Lehmann A, Burgess S, Harris M, Owens V (2001) Extending the cross-cultural validity of the theory of basic human values with a different method of measurement. J Cross Cult Psychol 32(5):519-542

Shaw D, Grehan E, Shiu E, Hassan L, Thomson J (2005) An exploration of values in ethical consumer decision making. J Consum Behav 4(3):185-200

Shuong J, Zhang C (2001) Least squares estimator of the mode of a unimodal regression function. Ann Stat 29(3):648-665

Sobotka F, Radice R, Marra G, Kneiband T (2013) Estimating the relationship between women's education and fertility in Botswana by using an instrumental variable approach to semiparametric expectile regression. J Royal Stat Soc Ser C62: 25-45

Thompson KE, Haziris N, Alekos PJ (1994) Attitudes and food choice behavior. Br Food J 96(11):9-13

Vega-Zamora M, Parras-Rosa M, Torres-Ruiz FJ (2020) You are what you eat: the relationship between values and organic food consumption.Sustainability 12(9):3900.

Verkasalo M, Lönnqvist J, Lipsanen J, Helkama K (2009) European norms and equations for a two-dimensional presentation of values as measured with Schwartz's 21-item portrait values questionnaire. Eur J Soc Psychol 39(5):780-792

Vermeir I, Verbeke W (2006) Sustainable food consumption: exploring the consumer "attitude-behavioral intention" gap. J Agric Environ Ethics 19(2):169-194

Zinkhan GM, Fontenelle SDM, Balazs AL (1999) The structure of Sao Paulo street markets: evolving patterns of retail institutions. J Consum Aff 33:3-26

\section{Publisher's Note}

Springer Nature remains neutral with regard to jurisdictional claims in published maps and institutional affiliations. 